\title{
Bullous impetigo in homosexual men-a risk marker for HIV-1 infection?
}

\author{
Basil Donovan, Richard Rohrsheim, Ingrid Bassett, Brian P Mulhall
}

\begin{abstract}
Objective-To determine the incidence of bullous impetigo in a group of homosexual men at high risk of HIV-1 infection.

Design-A longitudinal descriptive study (1984-9).

Setting-A private primary care and STD clinic in Sydney, Australia.

Subjects-88 homosexual men documented to seroconvert to HIV-1, and 37 homosexual controls who had practised unprotected anal intercourse with another man known to be HIV-1 positive but who remained HIV-1 negative.

Main outcome measure-Incidence of bullous impetigo.

Results-The crude annual incidence of bullous impetigo was 0.015 in subjects while they remained HIV-1 negative (10 cases) and 0.045 in early $\mathrm{HIV}-1$ positive subjects ( 2 cases). Overall, $9 \%$ of the HIV-1 seroconverters and $9 \%$ of the HIV-1 negative controls were documented as suffering bullous impetigo over a mean of 29.2 and 39.3 months, respectively.

Conclusions-Bullous impetigo in an adult could prove to be a clinical indication that a person is either infected with HIV-1 or is in close (possibly sexual) contact with a person with HIV-1 infection. If true, the recognition of bullous impetigo could provide an opportunity for behavioural intervention to limit the spread of HIV-1.
\end{abstract}

\section{Introduction}

Bullous impetigo is a cutaneous eruption usually due to phage group II strains of Staphylococcus aureus ${ }^{1}$ characterised by clusters of flaccid bullae containing purulent fluid $5 \mathrm{~mm}-8 \mathrm{~mm}$ in diameter. These bullae rupture within a few days to leave regular circular or oval superficial erosions, most commonly in flexural areas. At presentation, bullae are usually in various stages of their natural history (see fig). Entry of the organism may also require some pre-existing skin pathology. ${ }^{1}$

Clinically, bullous impetigo is easily distinguished from lesions caused by herpes simplex virus (HSV) which are smaller and more painful. HSV lesions may also be accompanied by systemic or regional symptoms. However, bacteriological testing may be required to distinguish bullous impetigo from superficial pemphigus. ${ }^{2}$
Bullous impetigo is mainly a seasonal disease of early childhood ${ }^{3}$ and was previously rare in adults. Reports of bullous impetigo, as well as other cutaneous staphylococcal conditions, in homosexual men with proven human immunodeficiency virus type 1 (HIV-1) infection $^{4-8}$ suggested that HIV-1 infection played a causal role.

An analysis of bacterial pathogenesis identifies several important mechanisms: adherence to host sites, penetration of anatomic barriers, disruption or avoidance of the host humoral defences, avoidance or inactivation of phagocytic cells, and production of toxins. ${ }^{9}$ Selective immunodeficiencies, involving immunoglobulins and/or defective neutrophilunction, predispose to staphylococcal disease. ${ }^{10-13} \mathrm{~B}$-cell abnormalities, namely a poor antibody response to novel antigens in the face of high immunoglobulin levels, are common in HIV-1 infection; ${ }^{14}{ }^{15}$ and neutrophil function is also impaired. ${ }^{16}$

However, the associations between HIV-1 infection and bullous impetigo in homosexually-active men may be both direct and indirect. We report below incidental findings which suggest that sexual contact with a person with HIV-1 infection may be a risk factor for bullous impetigo in HIV-1 negative persons.

\section{Subjects and methods}

Study group

The study group comprised every homosexually-active man attending Taylor Square Private Clinic, a private primary care and sexually transmissible disease clinic in central

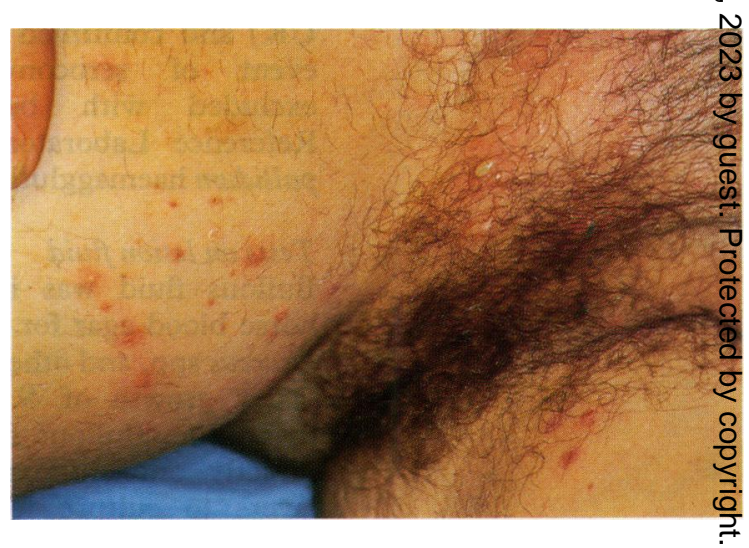

Figure Bullous impetigo in an HIV negatıve homosexual man. An intact bullus is present in his perineum, erosions left by ruptured bullae are on his left inner thigh, and folliculitis is present on his right inner thigh. \\ Centre, Sydney \\ Sydney, 2001 \\ B Donovan \\ I Bassett \\ Australia \\ 2 January 1992
}


Table Clinical and laboratory features of homosexually active men with bullous impetigo

\begin{tabular}{|c|c|c|c|c|c|}
\hline $\begin{array}{l}\text { Subject } \\
\text { number }\end{array}$ & $\begin{array}{l}\text { Month/year } \\
\text { of bullous } \\
\text { impetigo }\end{array}$ & $\begin{array}{l}\text { Weeks before }(-) \\
\text { or after }(+) H I V-1 \\
\text { seroconversion } \\
\text { illness }\end{array}$ & Site & $\begin{array}{l}\text { Culture for } \\
\text { S. aureus }\end{array}$ & $\begin{array}{l}\text { Culture for } \\
H S V\end{array}$ \\
\hline \multicolumn{6}{|c|}{ HIV-1 seroconverters: } \\
\hline 1 & $8 / 84$ & -234 & axilla & + & ND \\
\hline 2 & $9 / 84$ & -5 & groin (bilateral) & + & - \\
\hline 3 & $11 / 84$ & -208 & perianal & + & - \\
\hline 4 & $7 / 85$ & -19 & axilla (bilateral) & ND & ND \\
\hline 5 & $9 / 85$ & +24 & groin & + & ND \\
\hline 6 & $6 / 86$ & -40 & axilla & + & ND \\
\hline 7 & $10 / 87$ & $+9^{\star}$ & groin (bilateral) & + & ND \\
\hline 8 & $4 / 88$ & -17 & groin & + & ND \\
\hline \multicolumn{6}{|c|}{ HIV-1 negative controls: } \\
\hline & $10 / 84$ & NA & groin (bilateral) & + & - \\
\hline \multicolumn{6}{|c|}{ (first episode) } \\
\hline \multicolumn{6}{|c|}{$\begin{array}{l}10 \quad 12 / 85 \\
\text { (second episode) }\end{array}$} \\
\hline 11 & $1 / 88$ & NA & groin & + & ND \\
\hline
\end{tabular}

$\mathrm{ND}=$ not done, $\mathrm{NA}=$ not applicable,$+=$ positive,$-=$ negative.

*Subject 7 seroconverted to HIV-1 asymptomatically. His time of seroconversion was arbitrarily assigned to the mid-point between his last negative and first positive HIV-1 tests (18 weeks apart). active men. The mean age of the group as a whole in the mid-point of the study period (1984-1989) was 30.9 years (range 16-59 years), which was similar to the subset of men with bullous impetigo ( $31 \cdot 2$ years; range $21-42$ years).

\section{Incidence of bullous impetigo}

During the study period, the 88 seroconverters were monitored for a mean of $29 \cdot 2$ months: $23 \cdot 2$ months prior to HIV-1 seroconversion and six months after seroconversion. The HIV-1 negative controls were followed for a mean of $39 \cdot 3$ months. Thus the 10 cases of bullous impetigo detected in subjects while they remained HIV-1 negative and the two cases in (early) HIV-1 positive subjects (table) equated with crude annual incidences of 0.015 and 0.045 respectively. Overall, $9 \%$ of the seroconverters and $9 \%$ of the controls were documented as suffering from bullous impetigo at some stage.

Sydney, ${ }^{17}$ between February 1984 and December 1989 who satisfied either of the following criteria: (a) "HIV-1 seroconverters" ( $\mathrm{n}=88$ )-men documented to seroconvert from HIV-1 antibody negative to positive, or (b) "HIV-1 negative controls" ( $n=37)$ men whose clinical records were flagged because they were known to have practised unprotected anal receptive intercourse with another man known to be HIV-1 antibody positive, but who failed to seroconvert to HIV-1 after at least six months of follow up.

All of these men were involved in an ongoing study of the potential role of a wide range of anogenital lesions in facilitating the sexual transmission of HIV-1. Clinical and laboratory data were obtained by case-note review. Data collection on subjects who remained HIV-1 negative closed with their last visit before 31 December 1989. Data collection on subjects who became HIV-1 positive closed six months after seroconversion.

\section{Serological testing}

HIV-antibodies in sera were sought using two commercial enzyme immunoassays (Genetic Systems, USA, and Wellcome Laboratories, UK) and confirmed by Western blot in the event of seroconversion. Syphilis was excluded with both Venereal Disease Reference Laboratory tests and Treponema pallidum haemagglutination assays.

\section{Tests on lesion fluid}

Bullous fluid was inoculated directly onto horse blood agar for the detection of Staphylococcus spp. and other bacteria. A moderate to heavy growth of $S$. aureus was considered diagnostic. Bullous fluid was also inoculated directly onto human fibroblast cell monolayers to culture for HSV using standard methods.

\section{Results}

Demographics of subjects

All 125 subjects were Caucasian homosexually-

\section{Clinical features and response to therapy}

The groin was the preponderant site of the bullous impetigo lesions (table). However, as some patients presented because they thought these were due to HSV infection, this may be a biased finding. Local folliculitis accompanied most of the lesions. All lesions responded rapidly to short courses of oral flucloxacillin or erythromycin (4-6 days) and/or topical chlorhexidine, with only one recurrence of bullous impetigo in one subject (number 10; table) after eight months. Regular sexual partners were also recommended to use topical chlorhexidine.

Three subjects required subsequent treatment for other culture-confirmed staphylococcal disease over the next 3 to 34 months (all after HIV-1 seroconversion). These comprised one episode of each of the following-stye, cellulitis/folliculitis of the buttock, pubic folliculitis, and a nipple infection. Subject number 3 (table) had anorectal gonorrhoea concurrently with his perianal bullus impetigo.

\section{Discussion}

We were surprised by this finding of a significant incidence of bullous impetigo, an otherwise rare condition in $\mathrm{HIV}-1$ negative adults. Moreover, because it is often a mild and self-limiting condition or some patients may have sought treatment for bullous impetigo elsewhere, these incidence data should be seen as a minimum for this high risk HIV-1 negative population. Interestingly, a previous study had found a comparable incidence of bullous impetigo in HIV-1 negative homosexual men (though less than in HIV-1 positive men) and none in heterosexual controls. ${ }^{5}$

With the possible exception of subject number 2 (table), whose lesions preceeded a primary HIV-1 illness by five weeks, the temporal relationship between bullous impetigo and HIV-1 seroconversion did not imply that the condition had any direct role in facilitating the transmission of HIV-1.

One explanation for the appearance of 
bullous impetigo in HIV-1 negative homosexual men could be immune dysfunction, possibly due to the immunosuppressive effect of viruses of the herpes family. ${ }^{18}{ }^{19}$ However, these findings are controversial. ${ }^{20}$

As, by definition, all of our HIV-1 negative subjects were sexual partners of men with HIV-1 infection, it seems plausible that bullous impetigo in this group was a consequence of close contact with high levels of S.aureus carriage in their partners. Thus, the diagnosis of this condition in an adult could prove to be a clinical indication that a person is either infected with HIV-1 or is in close (possibly sexual) contact with somebody with HIV-1 infection. In either instance, the recognition of bullous impetigo could provide an opportunity for behavioural intervention to limit the spread of HIV-1.

This study was supported by a Commonwealth AIDS Research Grant. We thank Drs Finlayson, Mutimer, Price, and Robertson of Taylor Square Private Clinic for their careful clinical documentation, and Nan Jordan for preparation of the manuscript.

1 Piemont Y, Rasoamananjara D, Fouace JM, Bruce T Epidemiological investigation of exfoliative toxin-producing Staphylococcus aureus strains in hospitalized patients. ing Staphylococcus aureus strains
$J$ Clin Microbiol 1984;19:417-20.

2 Kouskoukis CE, Ackerman AB. What histologic finding distinguishes superficial pemphigus and bullous impetigo? Am J Dermatopathol 1984;6:179-81.

3 Rogers M, Dorman DC, Gapes M, Ly J. A three year study of impetigo in Sydney. Med J Aust 1987;147:63-5.

4 Muhlemann MF, Anderson MG, Paradinas FJ, et al. Early warning skin signs in Aids and persistent generalized lymphadenopathy. Br J Dermatol 1986;114:419-24.
5 Lang W, Anderson RE, Perkins H, et al. Clinical, immunologic, and serologic findings in men at risk for AIDS: the 257:326-30.

6 Farthing CF, Staughton RCD, Payne CME. Skin disease in homosexual patients with acquired immune deficiency homosexual patients with acquired immune deficiency
syndrome and lesser forms of human $T$ cell leukaemia vyndrome and lesser forms of human T cell le

7 Valle S-L. Dermatologic findings related to human immunodeficiency virus infection in high-risk individuals. J Am Acad Dermatol 1987;17:951-61.

8 Grodman DS, Teplitz ED, Wishner A. et al. Prevalence of cutaneous disease in patients with acquired immunodeficiency syndrome (AIDS) or AIDS-related complex. J Am Acad Dermatol 1987;17:210-20.

9 Hewlett EL. Other factors. In: Mandell GL, ed. Principles and Practice of Infectious Diseases. 2nd ed. New York: John Lisley, 1985:23-5.

10 Monteil M, Hobbs J, Citron K. Selective immunodeficiency affecting staphylococcal response. Lancet 1987;ii:880-3.

11 Quie PG, Hill HR, Todd-Davis A. Defective phagocytosis of staphylococci. Ann NY Acad Sci 1974;236:233-43.

12 Hobbs JR, Foroozanfar N. Neutrophil function and dysfunction. In: Truelove SC, Willoughby CP, eds. Topics in Gastroenterology: 7. Oxford: Blackwell, 1979: 193-203.

13 O'Driscoll M, Crawford L, Bigger WD. Clinical features and abnormal neutrophil function in disseminated staphylococcal disease. Ped Infect Dis 1985;4:137-41.

14 Lane HC, Masur H, Edgar LC, et al. Abnormalities of B cell activation and immunoregulation in patients with the acquired immunodeficiency syndrome. $N$ Engl J Med 1983;309:453-8.

15 Fauci AS. The human immunodeficiency virus. Infectivity and mechanisms of pathogenesis. Science 1988;239: 617-22.

16 Ellis M, Gupta S, Galant S, Hakim S, VandeVen C, Cairo MS. Impaired neutrophil function in patients with AIDS or AIDS-related complex: a comprehensive evaluation. J Infect Dis 1988;158:1268-76.

17 Donovan B, Finlayson RJ, Mutimer K, et al. HIV infection in sexually transmissible disease practice in Sydney: effects of legislation, public education, and changing clinical spectrum. Int J STD \& AIDS 1990;1:21-7.

18 Crapper RM, Frazer IH, Mackay IR, et al. Immunoregulatory defects associated with infection with the AIDS virus, HTLV-111. Concepts Immunopathol, Karger, Basel. 1987;4:243-60.

19 Mulhall BP, Naselli G, Whittingham S. Anticardiolipin antibodies in homosexual men: prevalence and lack of antibodies in homosexual men: prevalence and lack of
association with human immunodeficiency virus (HIV) association with human immunodeficiency
infection. $J$ Clin Immunol 1989;9:208-13.

20 Dobozin BS, Judson FN, Cohn DL, et al. The relationship of abnormalities of cellular immunity to antibodies to HTLV-111 in homosexual men. Cell Immunol. 1986; 98:156-71. 